\title{
Gestão da Informação como ferramenta no acompanhamento do estágio não obrigatório: análise do contexto do curso de Pedagogia presencial de uma Universidade Federal
}

\author{
Information Management as a tool in the follow-up of the supervised internship: analysis of the \\ context of the Pedagogy course at a Federal University
}

\author{
Teresinha Pereira da Rocha ${ }^{1}$, Pedro Alves Barbosa Neto ${ }^{2}$ \\ 1 ORCID: https://orcid.org/0000-0001-7588-1082/ \\ 2 ORCID: https://orcid.org/0000-0002-4741-5735
}

Autor para correspondência/Mail to: Pedro Alves Barbosa Neto, pedrocorone@hotmail.com

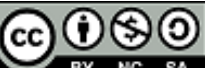

Copyright (C) 2019 Rocha \& Barbosa Neto. Todo o conteúdo da Revista (incluindo-se instruções, política editorial e modelos) está sob uma licença Creative Commons Atribuição-NãoComercial-Compartilhalgual 3.0 Não Adaptada. Ao serem publicados por esta Revista, os artigos são de livre uso em ambientes educacionais, de pesquisa e não comerciais, com atribuição de autoria obrigatória. Mais informações em http://revistas.ufpr.br/atoz/about/submissions\#tcopyrightNotice.

\begin{abstract}
Resumo
O estágio supervisionado não obrigatório é uma atividade que faz parte da formação profissional de muitos alunos de graduação e requer o acompanhamento por parte dos professores orientadores da instituição de ensino. Essa atividade produz informações tanto no âmbito interno como no âmbito externo à universidade, que são importantes para subsidiar as decisões da coordenação do curso quanto à formação acadêmica dos estudantes da graduação. A partir da questão: como a Gestão da Informação pode contribuir com o acompanhamento do estágio não obrigatório? Esta pesquisa teve como objetivo geral analisar a Gestão da Informação como ferramenta para o aproveitamento das informações no processo de acompanhamento do estágio não obrigatório. Para isso, os objetivos específicos definidos foram: evidenciar a importância das informações no acompanhamento do estágio não obrigatório e identificar aspectos da Gestão da Informação pertinentes ao acompanhamento do estágio não obrigatório. Trata-se de pesquisa bibliográfica e documental, caracterizada como exploratória e descritiva, com abordagem qualitativa, relacionada à coordenação de curso de Pedagogia de uma universidade pública federal. Constatou-se que a Gestão da Informação, por meio da estruturação de um fluxo de informações, serviria como ferramenta propícia para troca de informações entre a universidade e o campo de trabalho, incrementando o acervo informacional referente ao estágio não obrigatório, cuja temática permeia decisões administrativas e pedagógicas do curso.
\end{abstract}

Palavras-chave: Estágio não obrigatório; Pedagogia; Gestão da informação; Fluxo de informação.

\begin{abstract}
The supervised internship is an activity that is part of the professional training of many undergraduate students and requires the support of the faculty. This activity produces information both internally and externally at the university that supports the Chair of Program in the decision making regarded to the academic background of undergraduate students. Considering the question: how can Information Management contribute to keep up with the supervised internship? This research had as main objective to analyze the Information Management as a tool for the use of information in the process of support to the supervised internship. That way, the specific objectives were: to highlight the importance of the information in the support of the supervised internship and to identify aspects of the information management relevant to the support to the supervised internship. This is a bibliographical and documentary research characterized as exploratory and descriptive, with a qualitative approach. The Chair of Pedagogy from a federal public university was the object of study. It was verified that by structuring an information flow, Information Management would be a good tool for the exchange of information between the university and the field of work. It would increase the information collection related to the supervised internship.
\end{abstract}

Keywords: Supervised internship; Pedagogy; Information management; Information flow.

\section{INTRODUÇÃO}

O estágio supervisionado não obrigatório é uma etapa complementar na formação acadêmica dos estudantes de cursos de graduação, sendo de caráter opcional aos alunos. Ao participarem dessas atividades, uma importante relação entre o ambiente interno acadêmico e o ambiente externo, campo de trabalho, é estabelecida e propicia uma produtiva troca de informações.

Como os cursos de graduação da universidade pública são dinâmicos, em contínuo processo de melhoria, o acesso às informações produzidas na modalidade de estágio não obrigatória constitui um dos recursos estratégicos para embasamento das decisões em relação à formação dos estudantes no curso e sua adequação ao mercado de trabalho. No entanto, essas informações precisam estar acessíveis para serem recuperadas, tratadas e difundidas pela organização em pouco tempo (Starec, 2006).

Para a aprovação do estágio não obrigatório, a Lei de Estágio 11.788/2008, em vigência, determina, entre outras obrigações, que a instituição de ensino indique um professor orientador como responsável pelo acompanhamento efetivo e avaliação das atividades do estagiário (Brasil, 2008). Nesse sentido, o gerenciamento de informações envolvendo o acompanhamento do estágio poderia apresentar uma riqueza de informações para uso dos envolvidos. 
Entretanto, a legislação não estabelece procedimentos para um fluxo das informações produzidas, ficando sua estruturação a critério de cada instituição.

Norteada pela questão: “como a Gestão da Informação pode contribuir com o acompanhamento do estágio não obrigatório?", a presente pesquisa teve como objetivo analisar a Gestão da Informação (GI) como ferramenta para aproveitamento das informações referentes ao processo de acompanhamento do estágio supervisionado não obrigatório, tendo como objetivos específicos: evidenciar a importância das informações no acompanhamento do estágio não obrigatório e identificar aspectos da GI pertinentes ao acompanhamento do estágio não obrigatório.

Para atingir os objetivos propostos, foi realizada uma pesquisa bibliográfica, embasada na literatura existente, caracterizada como exploratória e descritiva. É exploratória por "[...] proporcionar visão geral, de tipo aproximativa, acerca de determinado fato" (Gil, 2008, p. 27), refletindo sobre o tema e evidenciando a sua importância; e descritiva, uma vez que descreve características de determinado fenômeno (Gil, 2008). Os resultados da pesquisa não estão embasados em mensuração e a análise de dados é interpretativa, caracterizando uma abordagem qualitativa (Flick, 2013).

A revisão de literatura buscou a teoria tanto na Ciência da Informação, na área da GI, como no campo da Educação, com o tema estágio, sobretudo não obrigatório. Para compreensão da realidade, também se adotou a pesquisa documental dos procedimentos do acompanhamento do estágio não obrigatório na coordenação de curso de Pedagogia de uma universidade pública federal.

Com essa pesquisa, a investigação no campo da GI reforça a importância dos conceitos da Ciência da Informação em diversos contextos organizacionais, inclusive na administração pública de ensino, cujo objetivo é a produção de conhecimento. Freire (2006, p. 17) indica como um dos objetivos da Ciência da Informação: contribuir para tornar a informação um elemento de inclusão social, "[...] trazendo desenvolvimento para as pessoas e nações". E o ingresso no mercado de trabalho, por meio de uma atividade com caráter formativo é, certamente, uma contribuição social importante na carreira desses estudantes.

\section{ESTÁGIO NÃO OBRIGATÓRIO: UM ATO EDUCATIVO COMPLEMENTAR À FORMAÇÃO ACADÊMICA}

Diversas formas de se compreender o estágio não obrigatório estão presentes nas regulamentações ao longo do tempo, em meio a diferentes contextos político-econômicos.

Em suas primeiras regulamentações, o estágio teve forte associação ao trabalho, estando mais próximo de um mecanismo de preparação de mão de obra do que de uma ação pedagógica (Colombo \& Ballão, 2014; Niskier \& Nathanael, 2006). Essa condição coadjuvante da ação pedagógica da atividade, sobretudo no caso dos estágios não obrigatórios, associou a essa modalidade de estágio a histórica imagem de espaço legal para obtenção de mão de obra barata.

A Lei de Estágio $n^{\circ} 11.788 / 2008$, atualmente em vigência, passou a vigorar em 2008, resgatando um caráter mais pedagógico à atividade de estágio, tanto obrigatório como não obrigatório. Nessa lei, o estágio é definindo como um "ato educativo escolar supervisionado, desenvolvido no ambiente de trabalho, que visa à preparação para o trabalho produtivo de educandos que estejam frequentando o ensino regular [...]"(Brasil, 2008) e descreve, também, que deve estar previsto no Projeto Pedagógico do Curso. Pela lei, o estagiário terá um supervisor na instituição concedente e um professor orientador na instituição de ensino. Evidencia-se, portanto, que ambas as modalidades de estágio, obrigatório e não obrigatório, são curriculares e supervisionadas.

Nota-se que, uma vez aprovada a realização do estágio não obrigatório, este se equipara ao estágio obrigatório, inclusive no que se refere ao acompanhamento obrigatório pela instituição de ensino e pela instituição concedente. Contudo, essa condição de equidade nem sempre ocorre nos corredores acadêmicos da formação de professores, pois verifica-se, ainda, pouco destaque para o não obrigatório.

A exigência do acompanhamento dos estágios caracteriza-se como uma proteção ao estudante de que a atividade será um complemento à sua formação. O estagiário vai ao campo profissional não somente para observar o que se faz, mas para integrar-se ao mundo do trabalho, correlacionando-o com a teoria estudada nos diversos componentes do currículo. Nesse aspecto, as instituições de ensino devem orientar o estagiário quanto às atividades relacionadas à sua área de formação, de forma que não prejudiquem seu desempenho acadêmico (Fujino \& Vasconcelos, 2011, p. 47) e assegurem o alinhamento do projeto de estágio com o perfil de egresso previsto no curso.

Destaca-se que os materiais informativos referentes ao estágio no âmbito da universidade e da própria coordenação do curso em estudo não indicam formas de obtenção de informações da atividade de estágio não obrigatório realizada pelos alunos, ou mesmo como as informações obtidas poderiam ser distribuídas aos demais professores do curso. 


\section{GESTÃO DA INFORMAÇÃO}

A informação, na sociedade atual, está presente nos diversos processos organizacionais, subsidiando todo tipo de ações e decisões. Entretanto, em um universo de grande oferta de informações, acessar e distinguir quais são aquelas úteis à organização é imprescindível. Antes disso, porém, há o desafio de identificar fontes disponíveis onde encontrar as informações relevantes para os processos de cada organização (Farias \& Vital, 2007). Nesse sentido, as organizações têm investido no gerenciamento das informações, o que justifica o crescente interesse na temática da GI.

A GI está relacionada a "[...] como a informação é criada, adquirida, organizada, armazenada, distribuída e usada como meio de promoção, acesso eficiente e eficaz à informação, processamento e uso por pessoas e organizações" (Detlor, 2010, p. 103, tradução nossa). Contribuindo ainda mais com aspectos organizacionais, "[...] o uso da informação envolve a seleção e o processamento da informação, de modo a responder a uma pergunta, resolver um problema, tomar uma decisão, negociar uma posição ou entender uma situação" (Choo, 2003, p. 107).

\section{Monteiro e Duarte (2018) apresentam uma síntese de como a GI pode ser compreendida:}

Em suma, a gestão da informação pode ser compreendida como um conceito amplo, um conjunto de atividades realizadas com a finalidade de controlar, armazenar e recuperar, de maneira eficiente, a informação produzida, recebida ou retirada, desde que traga benefícios para a organização em questão, na tomada de decisões e na possibilidade de inovar e de adquirir conhecimentos (Monteiro \& Duarte, 2018, p. 99-100).

Percebe-se, pois, a necessidade do gerenciamento da informação que, de acordo com Davenport (1998), se justifica, entre outros motivos, para a melhor utilização dos recursos disponíveis e para tornar a informação mais significativa.

No modelo da Ecologia da Informação de Davenport (1998), o processo de GI ocorre em etapas: determinação das exigências, obtenção, distribuição e utilização da informação. E, apesar de apresentar uma estrutura, o autor afirma que o processo de gerenciamento da informação, em cada organização, tem suas particularidades e pode sofrer modificações.

Nessa perspectiva, é pertinente concordar com Ferreira e Perucchi (2011, p. 447) quando dizem que "[...] sem a gestão, o fluxo de informação que circula nas organizações se dá sem orientação, desperdiçando informações relevantes ao desenvolvimento das organizações".

A busca por informações é um processo desafiador, uma vez que não se limita a responder uma questão isolada, e tampouco pode ser uma prática ocasional. Ela deve fazer parte de todos os processos e fluxos organizacionais (Teixeira \& Valentim, 2017). Cabe destacar que o estabelecimento de um fluxo de informações contribui para institucionalizar a maneira de lidar com a informação e influencia o comportamento informacional dos envolvidos.

Sendo uma organização, a universidade deve sempre aperfeiçoar sua forma de administrar. Desse modo, Starec (2003) entende a GI como uma ferramenta que contribuiria para a modernização no âmbito universitário, proporcionando fluidez de informações e, consequentemente, encaminhamento de diversas questões acadêmicas.

Para Rioga e Baracho (2016, p. 5), "[...] o fluxo informacional é essencial, porque ele vai desde a identificação da informação, até sua utilização, de acordo com as necessidades dos usuários". As autoras apontam o fluxo informacional como benefício para a rotina de uma organização. Essa posição é reforçada por Vital, Floriani, e Varvakis (2010, p. 92) ao afirmarem que "[...] o efetivo gerenciamento da informação em organizações passa por um processo contínuo de etapas estruturadas, organizadas e sistematizadas (fluxo de informação), pessoas atuantes no processo e responsáveis por tal gestão, além do uso otimizado das fontes de informação" (Vital et al., 2010, p. 92).

Há vários modelos de fluxos de informação descritos na literatura. Segundo Inomata, Araújo, e Varvakis (2015), os modelos não são aplicados integralmente a uma organização devido ao contexto particular de cada segmento, que exige adequações, sendo possível, inclusive, a combinação de modelos. Dessa forma, não se pode desconsiderar o contexto para a definição de um modelo de fluxo de informação.

Nesse sentido, esta pesquisa adota, como referência, o modelo de Beal (2004). A autora defende que a informação percorre um fluxo nas organizações, estruturado ou não. O modelo de fluxo de informações da autora apresenta sete etapas: identificação de necessidades e requisitos, obtenção, tratamento, distribuição, uso, armazenamento e, por fim, descarte. O fluxo prevê troca de informações entre o ambiente interno e externo.

A primeira etapa, identificação de necessidades e requisitos de informação dos indivíduos que integram a organização e do seu público externo, é um processo contínuo, realizado periodicamente, pois da dinâmica organizacional podem surgir novas necessidades. A partir dessa primeira etapa podem ser desenvolvidos produtos informacionais voltado para cada grupo e suas necessidades específicas (Beal, 2004). 


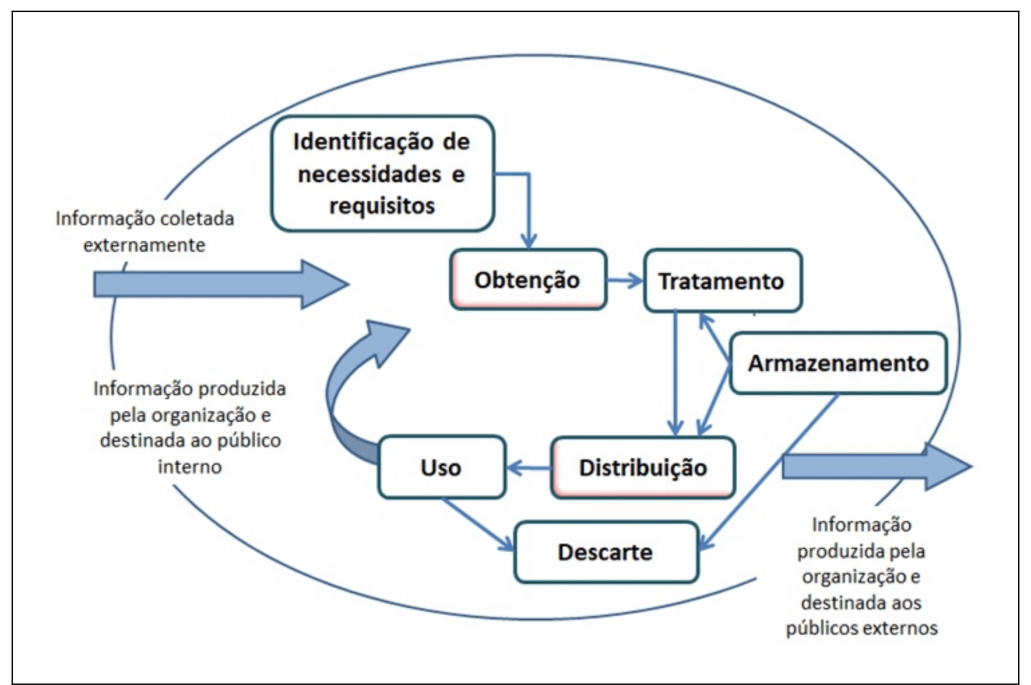

Figura 1. Modelo de fluxo da informação

Fonte: Adaptado de Beal (2004, p. 29)

Identificadas as necessidades é preciso supri-las. Assim, passa-se à segunda etapa, que é a obtenção de informações. Para a "[...] obtenção da informação são desenvolvidas as atividades de criação, recepção ou captura de informação, proveniente de fonte externa ou interna [...]" (Beal, 2004, p. 30). As fontes de informação utilizadas podem ser instituições, pessoas ou documentos (Beal, 2004; Davenport, 1998).

Após obtidas, as informações devem passar por organização, formatação, estruturação, classificação, análise, síntese e apresentação, que é a etapa de tratamento. Nessa etapa, busca-se tornar a informação acessível e de fácil localização, considerando a proteção de informações sigilosas (Beal, 2004).

Uma vez tratadas, a etapa seguinte é a distribuição das informações a quem delas precisa, sejam usuários internos ou externos. A melhor distribuição das informações propicia o seu uso nas decisões, contudo, seu melhor aproveitamento depende de como foi tratada na etapa anterior. Beal (2004) indica dois métodos pelos quais as organizações podem optar: método de divulgação e método de busca pelo usuário, embora considere uma combinação dos dois métodos o melhor sistema de distribuição, que consiste em fornecer determinadas informações ao usuário, mas também permite que outros dados possam ser recuperados o que, nesse caso, requer um bom sistema de busca e localização de informações.

A quinta etapa, uso, é considerada por Beal (2004) como a mais importante no fluxo da informação. O uso da informação pode ocorrer para satisfazer diferentes necessidades do usuário. Essas necessidades de uso são classificadas por Taylor (1968 citado por Choo, 2003, p. 109) em oito classes: esclarecimento, compreensão do problema, instrumental (como fazer), factual (descrever a realidade), confirmativa, projetiva de acontecimentos futuros, motivacional e pessoal ou política (criar relacionamentos).

Como forma de conservação dos dados e informações, Beal (2004) identifica a sexta etapa do fluxo, o armazenamento, que visa à manutenção da integridade e disponibilidade dos dados e informações existentes, permitindo o uso da informação diversas vezes na organização.

A última etapa é denominada descarte. As informações que se tornam obsoletas ou inúteis são descartadas para melhorar o processo de GI, respeitando algum critério: normas legais ou exigências internas.

Ao ser estruturado um fluxo de informação, este funciona como um instrumento para efetivar a GI, essencial para obtenção e acesso às informações, reforçado pela afirmação de Choo (2003) na qual aponta a GI como estratégia de localização de informações na organização que poderão contribuir com a produção de novos conhecimentos.

Diante disso, a aproximação da GI com o processo de acompanhamento do estágio não obrigatório parece ser de grande importância para o acesso às informações e sua introdução nas discussões administrativas e pedagógicas no âmbito do curso de Pedagogia.

\section{APROXIMAÇÃO DA GESTÃO DA INFORMAÇÃO COM O ACOMPANHAMENTO DO ESTÁ- GIO NÃO OBRIGATÓRIO}

O interesse pelo estágio não obrigatório no curso de Pedagogia presencial em estudo mobiliza muitos jovens sem experiência no mercado de trabalho e que veem no estágio uma oportunidade de ingressar no universo da profissão escolhida e, em alguns casos, a única condição de geração de renda durante o curso. 
Conforme dados da coordenação do curso, muitos desses alunos atingem os dois anos de atuação em uma mesma instituição concedente, limite da legislação atual, e uma minoria ultrapassa os dois anos ao firmar novo termo de compromisso, em outro local, somando uma significativa carga horária de estágio não obrigatório.

Entretanto, sem uma produção contínua de informações, há um resgate superficial da experiência na atividade de estágio não obrigatório. Isso prejudica uma análise mais detalhada de aspectos importantes vividos pelos estagiários e das implicações na formação desses alunos, bem como uma avaliação quanto às instituições concedentes inseridas nesse processo de formação.

Identificar bons espaços de atuação profissional é uma condição importante para o atual contexto político e econômico brasileiro, marcado por restrição de verbas para a educação e consequente redução em projetos que dependem de orçamento público. Os cortes em programas institucionais podem incentivar os alunos a buscarem novas experiências em campos de estágio não obrigatório e, especialmente, a geração de renda, condição de permanência no curso para muitos. Nesse cenário, esses alunos devem ser orientados a não frequentar ambientes que não valorizem a formação pedagógica da atividade.

Para as ações de acompanhamento do estágio não obrigatório, o procedimento comum identificado na universidade durante a pesquisa, obrigatório para todas as graduações, é a assinatura do Termo de Compromisso do Estagiário e o acesso ao módulo no sistema eletrônico instalado, atualmente restrito aos dados contratuais e relatório do estagiário. Há grande expectativa na implantação de novas funcionalidades.

O fluxo informacional do processo de acompanhamento do estágio supervisionado não obrigatório, visto além dos limites do sistema eletrônico, ocorre de forma dispersa. Ao assumirem o papel de acompanhamento do estágio não obrigatório e, sem uma indicação quanto ao que produzir a partir dessa atribuição, além das exigências previstas no sistema eletrônico, os professores orientadores adotam seus fluxos informacionais individualmente. É certo afirmar que a experiência dos alunos e sua relação com seus professores orientadores produzem, de maneira informal, muito mais informações do que o acervo disponibiliza.

Esse contexto apresenta-se como propício para a implementação da GI, pois por meio de um fluxo informacional estruturado, ela permite suprir as lacunas de informação, identificar fontes disponíveis, distribuir e permitir, mais do que o acesso a essas informações: a valorização da cultura de uso das informações. E, como ressaltam Ferreira e Perucchi (2011, p. 2011), "um dos objetivos da Gestão da Informação (GI) é apoiar as políticas organizacionais, amparando os gestores na tomada de decisão [...]".

Ao ter como referência o modelo de Beal (2004), a primeira etapa do fluxo de informação, a identificação de necessidades e requisitos dos indivíduos que integram a organização e do seu público externo, oferece ao acompanhamento do estágio não obrigatório elencar as informações sobre a adequação das experiências do estágio supervisionado não obrigatório ao curso de graduação com uma aproximação entre a universidade e as instituições concedentes, visando ao melhor andamento do processo de formação com projetos complementares. Afirmam Pimenta e Lima (2004):

Ao transitar da universidade para a escola e desta para a universidade, os estagiários podem tecer uma rede de relações, conhecimentos e aprendizagens, não com o objetivo de copiar, de criticar apenas os modelos, mas no sentido de compreender a realidade para ultrapassá-la (Pimenta \& Lima, 2004, p. 111).

Esse trânsito permite que o estágio seja uma oportunidade para o enfrentamento dos desafios e a atualização dos conhecimentos, não só para o estagiário, mas também para os professores orientadores e supervisores envolvidos (Barreiro \& Gebran, 2006). Dessa forma, a atividade estaria se prestando à formação inicial do estudante e à formação continuada dos profissionais das instituições concedentes. A força que a lei atribui ao professor orientador da instituição de ensino no acompanhamento propicia que ele seja um elo entre os envolvidos no processo, assumindo sua responsabilidade no percurso formativo do aluno e na qualidade do campo de estágio.

A indicação das necessidades de informações dos usuários permite investir na etapa seguinte, que é a de obtenção dessas informações por meio do uso de diversas fontes. A variedade de fontes contribui para a construção do que é, de fato, o estágio não obrigatório, integrando as visões e expectativas de todos os envolvidos: instituição de ensino, instituição concedente e aluno, acerca da atividade de estágio não obrigatório, evitando distorções em razão de conhecer somente a sua própria vivência.

Com a obtenção, o propósito da próxima etapa, tratamento, segundo Beal (2004), é tornar a informação acessível e de fácil localização. É o momento em que as informações passam por organização, formatação, estruturação, classificação, análise, síntese e apresentação. Davenport (1998) destaca o tratamento da informação como forma de criar maior interesse do usuário pela informação. Sem o tratamento, dificilmente as informações obtidas darão continuidade a outras etapas do fluxo.

A etapa de tratamento permite produzir material informacional para distribuição a todo o corpo docente ou à promoção de discussão em espaços de formação dos alunos, inclusive daqueles que não realizam o estágio 
supervisionado não obrigatório, com reflexões a partir das discussões das experiências dos colegas. A melhor distribuição das informações propicia o seu uso nas decisões.

$\mathrm{O}$ acesso às informações pelo corpo docente propicia o envolvimento do estágio com os demais componentes do curso, em oposição ao seu isolamento, pois a prática se constitui da articulação de todos os conteúdos da formação (Pimenta \& Lima, 2004). Constata-se, assim, que o estágio não é tema de alguns componentes, mas que deve ser uma discussão interdisciplinar na formação do aluno, possível somente com a distribuição e compartilhamento das informações.

Ao ser inserido nas discussões dos componentes curriculares, atinge-se a etapa de uso. Beal (2004) considera essa etapa como a mais importante no fluxo da informação. A autora justifica, citando Chaumier (1986), que é o uso, e não o fato das informações existirem, que garantem melhores resultados organizacionais.

Estrategicamente, o uso das informações em discussões pelo corpo docente e discente referente aos problemas enfrentados em situações de estágio pode promover o fortalecimento da preparação dos alunos em formação, que em pouco tempo assumirão suas carreiras profissionais, inclusive como supervisores de outros estagiários.

Como sexta etapa, Beal (2004) identifica o armazenamento como forma de conservação dos dados e informações, o que permite seu uso diversas vezes na organização, aumentando a possibilidade do estágio ser abordado como objeto de estudos.

O modelo de Beal (2004) apresenta, como última etapa, o descarte, implementado para descartar as informações que se tornam obsoletas ou inúteis, sendo desnecessária sua preservação.

Cabe destacar que as ações que promovem o acesso às informações da atividade de estágio não obrigatório podem levar a entendimentos entre as instituições envolvidas que contribuam com uma redefinição da imagem da atividade, muitas vezes associada à mão de obra barata. No entanto, em meio a tantas instituições concedentes com diferentes posturas em relação à formação do estagiário, há uma parte delas cujos projetos de estágio estão, de fato, complementando a formação acadêmica. A implantação da GI poderia produzir informações que permitissem essa discriminação nas ofertas de campo de estágio.

\section{CONSIDERAÇÕES FINAIS}

O acompanhamento do estágio supervisionado não obrigatório é um processo que permite o acesso da coordenação do curso às informações dessa atividade, bem como a troca dessas informações entre os sujeitos envolvidos, professores orientadores da instituição de ensino, supervisores das instituições concedentes e alunos, trazendo aspectos enriquecedores para o desenvolvimento da formação no curso.

O objetivo geral e os objetivos específicos da pesquisa foram atingidos, uma vez que foi realizada a análise da GI como ferramenta para aproveitamento das informações referentes ao processo de acompanhamento do estágio supervisionado não obrigatório, refletindo sobre a importância das informações e identificando os aspectos da GI pertinentes à atividade.

O estudo constatou a adequação de um fluxo de informações ao acompanhamento do estágio não obrigatório, demonstrando a aplicabilidade dos conceitos e ferramentas da GI nesse processo.

A implantação da GI como ferramenta para o acompanhamento do estágio não obrigatório traria um considerável incremento na gestão do curso. São muitos os benefícios que emergem: a capacidade da GI potencializar o acesso às informações produzidas nessa experiência dos alunos; a possibilidade de troca de informações entre ambiente interno e externo; o avanço do conhecimento e das discussões sobre essa modalidade de estágio na instituição concedente e na instituição de ensino.

Além disso, o estudo contribui com a divulgação dos conceitos da área de Ciência da Informação por promover o registro de informações, incentivando a documentação histórica de maior número de informações a respeito do estágio supervisionado não obrigatório e, portanto, expandindo a memória institucional. A gestão dessas informações possibilitará o acesso às informações sobre o tema, além de potencial expansão dos resultados para outras graduações, especialmente as licenciaturas, que assim como Pedagogia, também formam professores.

Muitas universidades que vivem a mesma realidade poderão beneficiar-se das reflexões promovidas neste estudo, avaliando seus fluxos de informação e refletindo sobre seus processos a partir da perspectiva da GI.

O encerramento deste trabalho não esgota as discussões a respeito da GI como ferramenta no acompanhamento do estágio não obrigatório, visto que desvenda uma série de possibilidades. A partir da elaboração de propostas de fluxo de informações, recomenda-se a análise de sua implantação e avaliação da evolução no sentido de satisfazer as necessidades dos usuários e intensificar seu aproveitamento. 


\section{REFERÊNCIAS}

Barreiro, I. M. d. F., \& Gebran, R. A. (2006). Prática de ensino e estágio supervisionado na formação de professores. São Paulo: Avercamp.

Beal, A. (2004). Gestão estratégica da informação: como tranformar a informação ea tecnologia da informação em fatores de crescimento e de alto desempenho nas organizações. São Paulo: Atlas.

Brasil. (2008). Lei $n^{\circ} 11.788$, de 25 de setembro de 2008. Dispõe sobre o estágio de estudantes. Recuperado de http://www.planalto.gov.br/ccivil_03/_ato2007-2010/ 2008/lei/111788.htm

Chaumier, J. (1986). Analisis y lenguajes documentales. Barcelona: Mitre.

Choo, C. W. (2003). A organização do conhecimento: como as organizações usam a informação para criar significado, construir conhecimento e tomar decisões. São Paulo: Senac.

Colombo, I. M., \& Ballão, C. M. (2014). Histórico e aplicação da legislação de estágio no Brasil. Educar em Revista, 53, 171-186. Recuperado de http://www.scielo.br/pdf/er/n53/ 11.pdf

Davenport, T. H. (1998). Ecologia da Informação: por que só tecnologia não basta para o sucesso na era da informação. São Paulo: Futura.

Detlor, B. (2010). Information management. International Journal of Information Management, 30, 103-108.

Farias, G. B. d., \& Vital, L. P. (2007). Informação para negócios e políticas de informação. Revista ACB: Biblioteconomia em Santa Catarina, 12(1), 87-98. Recuperado de https://revista.acbsc.org.br/racb/article/view/497/642

Ferreira, T. E. d. L. R., \& Perucchi, V. (2011). Gestão e o fluxo da informação nas organizações: um ensaio a partir da percepção de autores contemporâneos. Revista $A C B$ : Biblioteconomia em Santa Catarina, 16(2), 446-463. Recuperado de https://revista.acbsc.org.br/racb/article/view/ $781 /$ pdf 61

Flick, U. (2013). Introdução à metodologia de pesquisa: um guia para iniciantes. Porto Alegre: Penso.

Freire, G. H. (2006). Ciência da informação: temática, histórias e fundamentos. Perspectivas em ciência da informação, 11(1), 6-19. Recuperado de http://www.scielo.br/pdf/pci/ v11n1/v11n1a02

Fujino, A., \& Vasconcelos, M. d. O. (2011). Estágios: reflexões sobre a ação didático-pedagógica na formação do profissional da informação. CRB-8 Digital, 4(1), 6-19. Recuperado de https://www.researchgate.net/ profile/Asa_Fujino/publication/303994086_Estagios _reflexoes_sobre_a_acao_didatico-pedagogica_na formacao_do profissional da informacao/links / 57621edd08ae5c6f86da84f8/Estagios-reflexoes-sobre-a -acao-didatico-pedagogica-na-formacao-do-profissional-da -informacao.pdf

Gil, A. C. (2008). Métodos e técnicas de pesquisa social (6a. ed.). São Paulo: Atlas.

Inomata, D. O., Araújo, W. C. O., \& Varvakis, G. (2015). Fluxos de informação na perspectiva organizacional. Informação \& Informação, 20(3), 203-228. Recuperado de http://www.uel.br/revistas/uel/index.php/informacao/ article/view/18209/17645

Monteiro, S. A., \& Duarte, E. N. (2018). Bases teóricas da gestão da informação. InCID: Revista de Ciência da Informação e Documentação, 9(2), 89-106. Recuperado de http://www.periodicos.usp.br/incid/article/view/ $133677 / 148275$

Niskier, A., \& Nathanael, P. (2006). Educação, estágio e trabalho. São Paulo: Integrare Editora.

Pimenta, S. G., \& Lima, M. S. L. (2004). Estágio e Docência. São Paulo: Cortez.

Rioga, D. C. P., \& Baracho, R. M. A. (2016). A Gestão da informação aplicada ao processo de internacionalização universitária: um estudo de caso da UFMG. Pesquisa Brasileira em Ciência da Informação e Biblioteconomia, João Pessoa, 12(1), 3-11. Recuperado de http://www .brapci.inf.br/index.php/article/download/54489

Starec, C. (2003). A questão da informação estratégica no ensino superior: os pecados informacionais e barreiras na comunicação da informação para a tomada de decisão na Universidade Estácio de Sá (Dissertação de mestrado, Universidade Federal do Rio de Janeiro, Rio de Janeiro). Recuperado de http://ridi.ibict.br/bitstream/123456789/ 718/1/claudiostarec2003.pdf

Starec, C. (2006). A dinâmica da informação: a gestão estratégica da informação para a tomada de decisão nas organizações. Gestão estratégica da informação e inteligência competitiva. São Paulo: Saraiva, 47-64.

Teixeira, T. M. C., \& Valentim, M. L. P. (2017). Processo de busca e recuperação de informação em ambientes organizacionais: Uma reflexão teórica sobre a subjetividade da informação. Perspectivas em Ciencia da Informacao, 22, 8297. Recuperado de http://portaldeperiodicos.eci.ufmg.br/ index.php/pci/article/view/2938/1983

Vital, L. P., Floriani, V. M., \& Varvakis, G. (2010). Gerenciamento do fluxo de informação como suporte ao processo de tomada de decisão: revisão. Informação $\mathcal{E}$ Informação, 15(1), 85-103. Recuperado de http://www.uel.br/revistas/ uel/index.php/informacao/article/view/5335/5880

Rocha, T. P. \& Barbosa Neto, P. A. (2019). Gestão da Informação como ferramenta no acompanhamento do estágio não obrigatório: análise do contexto do curso de Pedagogia presencial de uma Universidade Federal. AtoZ: novas práticas em informação e conhecimento, 8(2), 69 - 75. Recuperado de: http://dx.doi.org/ 10.5380 /atoz.v8i2.71519 